\title{
Space Traffic Coordination: Developing a Framework for Safety and Security in Satellite Operations
}

\author{
P. J. Blount $\mathbb{D}$ \\ University of Luxembourg, Luxembourg \\ Correspondence should be addressed to P. J. Blount; pjblount@gmail.com
}

Received 4 February 2021; Accepted 26 April 2021; Published 23 May 2021

Copyright (C) 2021 P. J. Blount. Exclusive Licensee Beijing Institute of Technology Press. Distributed under a Creative Commons Attribution License (CC BY 4.0).

\begin{abstract}
This article investigates the extant normative framework that can be identified around the concept of space traffic management (STM). While much of the STM literature engages with how a future regime might be structured, this article attempts to engage with current processes related to space traffic coordination and give insight as to how normative growth toward space traffic management might occur. Through a survey of current legal and governance mechanisms, this article focuses its attention on open data sharing as an extant and critical coordination process that has potential for normative growth in the development of space traffic management as a formal regime.
\end{abstract}

\section{Introduction}

The idea of customary international law is a slippery concept as it requires lawyers to construct rules from thin air, so to speak, rather than to interpret an epistemic text such as a statute or a judicial decision. In short, customary international law requires the lawyer to identify widespread state practice (i.e., that states are doing a thing) and corresponding opinio juris (i.e., that states are doing this thing because they believe it is a legal obligation) $[1,2]$. Under these conditions, the "text" that the lawyer must "read" is an amalgam of artifacts that indicate that there is a general belief in an unwritten rule. The concept of customary international law gets muddled even further in the space context wherein one must contend through Cheng's theory of "instant customary international law," under which a single instance of state practice can result in the emergence of customary international law [3-5]. For instance, it can be argued that the orbiting of Sputnik $I$ and the complete lack of objections to its flights established the right of overflight in space and the correlated idea that space is outside of national jurisdiction [6]. Under this theory, the launch of Sputnik I was not just a tremendous accomplishment; it was also an act of fundamental norm creation. The theory of instant custom is, of course, a fascinating way to think about the creation of the legal normative framework, but it obscures the fact that norms generally take time to build to the strength of law. Indeed, the very premise of custom is that preceding the establishment of a norm, there is a period of time in which states coordinate their behavior in such a way that the law is asserted through the repetition of acts and statements. This period of establishing the law is critical to the establishment of customary international law, because this repetition of the legal maxim through actions and evidentiary artifacts create the evidence of the opinio juris.

The aim of this article is not to engage in a discourse of customary law, but rather to argue, in the context of space traffic management, that the present iteration of potential norms can be seen as the evidence of future norms and is worthy of investigation. In other words, it examines contemporary practice as locus of repetition of potential future norms. This article argues that the objective of space traffic management (STM) will be preceded by a period of space traffic coordination, through which states can choose among governance options that could lead to STM. It asserts that we are currently at the threshold of that coordinating phase as a norm of information sharing is emerging in the practice and opinio juris of states, though this norm has yet to be fully formed. To build this argument, this article surveys the current state of play in STM from a law and policy perspective to seek out the evidence of a potential emerging cooperative order. This is an important exercise because from a legal perspective, regardless of whether STM emerges as a customary normative order or a treaty-based system or not at all will 
depend on a great deal on whether states and other organizations can effectively find avenues for coordination of space activities.

This article will proceed first by examining the difference in the concepts of management and coordination and making the case that we are entering a phase in which space traffic coordination may emerge. Next, this article will give a survey of the current state of coordination of space activities to identify emerging trends that can help to understand how the governance system may grow and evolve. This article will then examine how this system may make the leap from coordinative practices and harden into legal frameworks, and finally, it will address a central challenge to the emergence of STM from coordination in the reliance on liability law as a guide.

\section{Management and Coordination}

Space traffic management has become an important concept in the space community attracting attention from both the technical and the law and policy sides of the field. There seems to be universal interest in how to manage space operations so as to avoid harmful interference with other space operations. This is rightfully so as there is growing recognition that as more states and nongovernmental actors engage in space activities, there will be increased risk posed by the growing population of space objects. This problem is amplified as operators are now pursuing satellite systems based on architecture concepts that employ large constellations. These new activities naturally lead to an increased risk of collision between or among space objects. At the same time, there has been little multilateral action towards effectuating a significant change in the governance system geared towards implementing STM at an international level. This section posits that the term "space traffic management," a phrase coined from the concept air traffic management, may set the bar too high in the current geopolitical atmosphere and that in the near term there should-and will likely be-more focus on establishing practices of "space traffic coordination" as a way to increase the safety and security of the space environment.

A well-known trope in the space law discourse is that after the negotiation of the Moon Agreement in 1979 the lawmaking phase of the United Nations Committee on the Peaceful Uses of Outer Space (UNCOPUOS) ceased [7-9]. Some commentators have bemoaned this situation and argue that there is still much to be elaborated in treaty frameworks, while others have noted that the shift has been to the development of "soft law" and domestic law to fill the gaps left in the international system. Regardless of perspective on the cessation of lawmaking, it is important to understand why states are no longer engaging in negotiating multilateral space law documents as this is significant to understanding how the development of space traffic management may progress.

To some extent a clear picture of this can be seen not when examining COPUOS, wherein the five major space law treaties originated, but instead through examining the nongrowth of space law in the security context. At the inter- national level, the concept of the Prevention of an Arms Race in Outer Space (PAROS) been pushed as a platform for building new rules for reducing the risk of conflict in outer space, but it has repeatedly failed to produce meaningful results. In Meyer's words,

If an extra-terrestrial were to land on planet earth and inquire politely after what was being done about ensuring the security of outer space, he/she/it would be struck by an apparent paradox. On the one hand there would appear to be a strong, almost universal consensus that states should reinforce the existing legal regime applicable to outer space to enhance its effectiveness. On the other hand, there has been no real progress by these same states in achieving this goal [10].

This can clearly be observed at the international level. An annual resolution on PAROS is passed by the UN General Assembly with near unanimous support, with only the United States and a couple of allies either abstaining or voting against it [11]. PAROS is also under the competency of the Conference on Disarmament (CD). Though a space arms control treaty has been proposed in this forum by Russia and China [12], the CD remains deadlocked after more than two decades $[13,14]$. Attempts to use other fora have also failed. The European Union sought to negotiate a political nonlegally binding Code of Conduct for space activities, but the negotiations stalled as states argued that the forum of negotiation and the substance of the agreement were inappropriate $[15,16]$. More recently, the UN convened Group of Governmental Experts on PAROS failed to adopt a final report [17].

What can be seen from these space security examples is that states, at the moment, seem reluctant not only to adopt new rules for outer space activities but also to even sit down at the negotiating table. Much of this can be traced to post-Cold War geopolitics and the transition from bipolar international relations to unipolar and then multipolar international relations. At the core though is a traditional reluctance to give up freedom of action in a domain that is both strategic and fraught with ambiguity. There has been a resurgence of military posturing in space since the turn of the century [18]. Since 2007, there have been multiple antisatellite weapon tests and numerous states have established new military entities focused on the space domain [19-25]. This has been matched with increasingly pugilistic rhetoric regarding the space domain, such as the United States' recent proclamation that space is a "warfighting domain" [26].

The concept of space traffic management, while invoking the civil functions of air traffic management, is wrapped in this quickening securitization of space. While operators of all types understand that there needs to be a way to prevent or minimize potential conjunctions in space, states in contemporary geopolitics tend to approach space law in such a way that they emphasize freedom of action in space as critical to their national interest and new rules as inimical to their power in that domain-even when those rules could potentially benefit military operators. States seem even more reluctant to enter into treaty arrangements that establish new international bodies or authorities that have supranational competencies. This is where the idea of "management" 
becomes problematic. The concept of management is linked to ideas of "supervision" and "control." In the STM context, it is impossible to ignore the clear connotations in echoing "air traffic management." Air traffic management is a broad term and encompasses numerous activities that contribute to the safety of flight operations, but it importantly involves the idea of air traffic control $[27,28]$. "Management" and "control" both imply authority, and states seem reluctant to enter into arrangements that lead to authority in space.

Since states are currently opposed to the development of supranational authorities to cope with increased space operations, establishing a functioning system of space traffic management may well be beyond the reach of the international community in the current geopolitical paradigm. It is submitted here that in the near term a more realistic goal is to pursue space traffic coordination, which would require a lower level of state commitment to binding rules, and instead focus on establishing frameworks for communication and knowledge sharing creating actionable data sets that space operators can rely on to coordinate their activities. Coordination, significantly, creates the ability for international action without the need for supranational authorities. These types of arrangements are often referred to as "soft law," which represents a "broad class of deviations from hard law" through which states can adjust the "combinations of obligation, precision, and delegation" in the governance frameworks they adopt [29]. Indeed, the notion of soft law has become a point of engagement in the international space law discourse [30].

Two examples can serve as indications of how states pursue such coordination. The first example is the Agreement Between the Government of The United States of America and the Government of The Union of Soviet Socialist Republics on the Prevention of Incidents On and Over the High Seas [31]. This bilateral agreement laid out rules for US and Soviet Naval forces that led to predictability in the actions of the other in an attempt to reduce the risk of naval incidents that could spark conflict. Specifically, this agreement laid out rules for maneuvers that allowed ship captains to recognize "normal" behavior and avoid unnecessary conflicts. A second example can be found in the International Code of Conduct against Ballistic Missile Proliferation. This nonbinding agreement facilitates the exchange of information on ballistic missiles and space launch vehicles including prelaunch notifications [32]. Such information exchange allows states to coordinate activities to avoid interference and reduce the risk of conflict.

What both of these examples show is that states can adopt frameworks that are not necessarily legally binding in order to guide their activities in such a way as to provide transparency to other states. Transparency allows for some extent of self-ordering among operators. For example, if a state puts other states on notice of the proposed orbital parameters of a planned mission, other states can ensure that their own domestic activities, whether governmental or private, will not interfere. Indeed, this author has argued before that such de minimis information sharing is required to enable the Outer Space Treaty Article IX consultation provisions by informing other states so that they may make a determination as to whether there is potential harmful interference [33]. Coordination of activities is reliant on such information sharing and can create the conditions for increased safety and security and decreased risk.

The idea of space traffic coordination, then, presents a path forward that is not burdened by the strictures of the term management. This is not to argue that the goal of an STM system should be abandoned altogether. If a thriving space economy is to be achieved at some point, a fullfledged STM system will be needed, but more time may be needed in the governance laboratory before a normative order can harden into law either through custom or treaty.

\section{State of Play in STM}

As noted in the introduction to this article, space traffic management is still very much in a development phase, and to discern what a future normative order might look like, one must first take stock of the contemporary governance frameworks that have the potential to contribute to shape any potential order. Current frameworks create the possible imaginaries of future structures. This section attempts to briefly take stock of what constitutes the current practice of space traffic coordination in order to elaborate where we currently stand on the establishment of true space traffic management. Rather than postulating what the best norms for STM should be, this section attempts to identify the extant norms and contextualize them in the development of the law. Broadly, this section will address international frameworks, domestic frameworks, and commercial frameworks. It should be noted here that this section will attempt a broad overview rather than deep analysis of each of the addressed topics. Such analysis would be beyond the scope of this article, but the reader is commended to the footnotes which include a number of relevant resources for further reading.

3.1. International Frameworks. At the international level, the contemporary framework emphasizes information sharing among space actors, though there are few hard obligations imposing mandatory information sharing. As noted above, information sharing is critical to transparency in operations that enable other actors to make informed decisions about their own operations. This subsection will investigate the current mechanisms within the international community contributing to space traffic coordination. Specifically, it will address the international treaty regime for outer space, work on space debris and the long-term sustainability of space, and the system for coordination of usage of the geosynchronous orbit under the ITU.

3.1.1. The Space Treaty Regime. The creation of international space law occurred rapidly after the launch of Sputnik $I$ in 1957. The Outer Space Treaty $[34,35]$ was adopted a mere ten years after the launch, and its main principles were elaborated even earlier in the Declaration of Legal Principles resolution adopted by the UN General Assembly in 1963 [36]. At the time of the adoption of the Outer Space Treaty, there 
was a great deal of uncertainty on how space technology would develop. The treaty itself only mentions a handful of potential technologies-such as launch and human spaceflight-that were already established activities. To this end, the Outer Space Treaty, instead of adopting rules pertaining to specific technologies, adopted broad principles that were technologically neutral. At the core of these principles are the concepts of cooperation and information sharing, and seemingly a core goal of the Outer Space Treaty is to create a legal environment in outer space that enabled and facilitated multilateral coordination. This can be seen in both the usage of the term "international cooperation" which appears more than any other legal term in the treaty (Preamble, Art. I, Art. III, Art. IX, Art. X, and Art. XI) and the number of clauses that contain provisions for information sharing among space actors (Art. V, Art. VIII, Art. IX, Art. X, Art. XI, and Art. XII) [37]. Thus, the OST serves as a foundational document to the project of coordination among space actors as it attempts to set the conditions for multilateral engagement in space activities. It, of course, must be noted that most of these information sharing requirements are on a best effort basis rather than mandatory hard obligations. Despite the soft nature of most these obligations, they serve as basis for increased transparency in the space domain. In this context, Article XI is indicative. It states that "[i]n order to promote international cooperation" state parties "agree to inform the Secretary-General of the United Nations as well as the public and the international scientific community, to the greatest extent feasible and practicable, of the nature, conduct, locations, and results" of space activities. Such provisions, while not binding states to a specific obligation, can be said to contribute to an underlying ethic adopted within the treaty to engage in space activities with transparency.

In addition to these soft treaty norms, states negotiated and adopted the 1976 Registration Convention to establish harder rules on information sharing $[38,39]$. The Registration Convention requires states to maintain a domestic registry of space objects (Art II). It also establishes a UNmaintained registry (Art. III) with full and open access. This registry is currently maintained by the UN Office for Outer Space Affairs [40]. Under Article IV, states are required to submit information about launched objects "as soon as practicable" after the launch to the UN registry. This information includes the following:

(a) Name of launching State or States

(b) An appropriate designator of the space object or its registration number

(c) Date and territory or location of launch

(d) Basic orbital parameters, including

(i) nodal period

(ii) inclination

(iii) apogee

(iv) perigee

(e) General function of the space object
State practice under the treaty has been incomplete at best with UNOOSA stating that $86 \%$ of all satellites have been registered [41]. For instance, significant lag time between launch and registration has been noted [42] and some space objects have not been registered [43]. Despite the deficiencies in state practice under the Convention, it does serve as a basis for a positive exchange of information on space activities and creates a data source that states can use when planning space activities to ensure that their operations do not cause and are not subject to interference. One of the key problems with the UN Registry though is that the data itself is often deficient. The treaty does not require states to update the information they have submitted if there is a change, for instance if the orbital parameters are changed or the spacecraft. Article IV(3) does mandate that states update the Secretary-General when a registered object is no longer in orbit, but the clause includes the common softening language that this shall be done "to the greatest extent feasible and as soon as practicable." To this end, UNOOSA supplements the data from open sources when possible [44].

The Registration Convention attempts to facilitate transparent space operations by creating an open data source for these operations. While the actual register falls short of fulfilling this goal, the Convention serves as an important way point for the creation of data sources that can facilitate the coordination of space traffic in the future.

3.1.2. Debris Mitigation. Debris mitigation guidelines have been adopted at the international level by both the Interagency Debris Coordination Committee (IADC) [45] and UNCOPUOS [46]. Both of these instruments are nonbinding technical guidelines with the goal of limiting the creation of new debris. This goal itself is important to space traffic coordination as it reduces the number of objects with which an operator must contend, thereby reducing the overall risk profile of an operation.

Both sets of guidelines include similar provisions on preventing on orbit collisions. The IADC formulation is

In developing the design and mission profile of a spacecraft or orbital stage, a program or project should estimate and limit the probability of accidental collision with known objects during the spacecraft or orbital stage's orbital lifetime. If reliable orbital data is available, avoidance manoeuvres for spacecraft and co-ordination of launch windows may be considered if the collision risk is not considered negligible. Spacecraft design should limit the consequences of collision with small debris which could cause a loss of control, thus preventing post-mission disposal.

This guideline requests that operators consult data and design their missions in such a way as to minimize their potential for interference. This goal is directly in line with those of space traffic coordination. Obviously though, this requires the operator to have access to data that can enable such design, and as seen above, such data is only partially available at the international level in the form of the UN Register. This leaves space operators to seek this data either from domestic governmental sources or from commercial sources, both of which are discussed below. 
3.1.3. The Long-Term Sustainability Guidelines. In 2018 UNCOPUOS adopted the first batch of principles in the Long-Term Sustainability Guidelines [47]. The nonbinding guidelines emerged from the Scientific and Technical Subcommittee of UNCOPUOS, which is significant as, like the previously discussed debris mitigation guidelines, they are intended to be technical in nature rather than regulatory [48].

These guidelines seek to lay out standards for ensuring the long-term sustainability of the space environment. They encourage states to engage in increased information sharing on space activities through a variety of mechanisms. For example, A.5 encourages states to register their space objects. Most significantly though are the $\mathrm{B}$ series of guidelines related to the "safety" of space operations.

These include the following:

(i) Guideline B.1: provide updated contact information and share information on space objects and orbital events.

(ii) Guideline B.2: improve accuracy of orbital data on space objects and enhance the practice and utility of sharing orbital information on space objects.

(iii) Guideline B.3: promote the collection, sharing, and dissemination of space debris monitoring information.

(iv) Guideline B.4: perform conjunction assessment during all orbital phases of controlled flight.

(v) Guideline B.5: develop practical approaches for prelaunch conjunction assessment.

This set of guidelines is directly related to space traffic management activities, but rather than regulate, the LongTerm Sustainability Guidelines attempt to create the conditions for coordination through robust information sharing. This focuses on the conditions for cooperation rather than rules creating a space in which states can explore rules upon which to base a potential normative order and that space is built around information sharing.

3.1.4. ITU. The ITU system for coordinating activity on the geostationary orbit (GEO) is the best example of an extant space traffic management system, but quite significantly, the ITU management of GEO is at its core a coordination regime. Due to its unique traits, the GEO is a valuable orbit for telecommunication satellites [49]. These satellites depend on a lack of radio frequency interference in order to operate. The ITU was given competency to manage the GEO in order to prevent harmful interference, and to effectuate this, the ITU has divided the GEO into slots and assigned a frequency to each slot [50]. States are able to claim slots by registering such a claim in the Master International Frequency Register (MIFR) [51]. This gives them priority over that frequency. After a temporal lapse if the state or the state's licensee has not brought a system into use at that frequency, the ITU will remove the notice from the MIFR [52]. The core of this system and the complex process that surrounds it is a registration and notice system. In this system, states register their use of a slot thereby putting other states on notice, which gives the registering state some degree of priority to use the orbit-spectrum resource claimed. This is important because GEO satellites are bespoke high value assets; thus, notice of an intent to use a particular orbital slot is an important factor during the multiyear development and procurement phase. While there is a forum for a weak dispute resolution regime [53], the ITU merely sets the conditions for coordination through procedural information sharing.

3.2. National Frameworks. National systems for management of space situational data are also relevant to the current state of space traffic coordination. While a number of states are active in this field, this article will primarily address actions taken by the United States, as it has made a significant contribution to space traffic coordination.

3.2.1. United States. The United States has built out a Space Surveillance Network for the collection of Space Situational Awareness (SSA) data [54]. This system is a military system based on the early warning system the US deployed during the Cold War, and as a result, the data is collected and analyzed by the United States Military. Despite its military nature, the United States shares this data widely. Under US Law [55], SSA data is shared at different levels with different entities. Highly accurate data that includes the classified satellite data is shared only with close allies. Some data is shared on the basis of bilateral agreements and can include high accuracy data but not necessarily include classified data. Finally, a set of data is distributed in an essentially open data model that anyone can access through the Internet [56]. In addition to this data sharing, if the U.S. military calculates that there is a significant risk of an on-orbit conjunction, they will notify the affected operators of their national embassies [57]. Thus, the United States shares much of this military data as a public good.

The United States has also shown an interest in developing a civil space traffic management capability. Under discussion since at least 2014 [58], STM came to the forefront of US Space Policy with the Trump administration's issuance of Space Policy Directive-3 on Space Traffic Management [59]. It should be emphasized that SPD-3 is a policy directive and only sets out the administration's approach to space traffic management rather than any sort of binding law or regulations. There are three notable features to this policy. This first is that while the collection of SSA data will remain a military mission, the policy seeks to move data distribution and the Conjunction Data Message (CDM) function to a civil agency [60]. Second, the policy endorses pursuing international cooperation in the pursuit of effective STM [61]. Finally, and most significantly, the policy endorses the establishment of an "open architecture data repository" that is available publicly and supported by open standards and data sharing [62]. This final point is significant as the US policy seeks to develop "standards and protocols" that will enable the "incorporat[ion] civil, commercial, international, and other available data" into the data pool for the benefit of "all" users. 
3.2.2. Other States. Other states also collect and share SSA data, though none with as robust a framework as the United States. Russia and China as major space actors both have SSA capabilities, but the extent of their data sharing is less clear [63]. China is leading, through the auspices of the AsiaPacific Space Cooperation Organization, the development of a global optical network called Asia-Pacific Groundbased Optical Space Objects Observation System (APOSOS) [64]. The EU is also seeking to bolster its capabilities and has plans to make the collection and sharing of SSA data one of the EU "flagship" space programs [65]. Even small states like Luxembourg [66] and the UAE [67] are entering the field in hopes of contributing to ensuring safety in the space environment.

It is notable that one of the biggest constraints on SSA collection and therefore highly accurate data is geography. SSA data can only be collected when a satellite is on the horizon. The United States has been able to leverage its global military holdings to establish a more complete space surveillance network, but even it suffers from a lack of coverage in the Southern Hemisphere. Smaller states have no way of building a complete orbital picture without gaining access to data from sensors outside their territory. As more space actors emerge, the need for states to have access to accurate data will increase, but without access to geographically remote sensors, states will be unable to provide this type of data on their own. This underscores the multilateral nature of the space traffic coordination problem as it requires global partnerships for any one actor to gather a complete picture of the orbital environment.

3.3. Commercial Actors. In addition to international and national initiatives, there are a number of commercial actors in the field, such as Exoanalytic Solution [68] and Leolabs [69]. These companies collect and analyze SSA data and sell data products to operators.

Also of note in this category of activity is the Space Data Association (SDA), which is an international association of commercial space operators that share SSA data among themselves, so as to better ensure collective safety [70]. In addition, to sharing among themselves, SDA has signed a bilateral agreement for sharing SSA date with the US Military, as discussed above [71].

\section{The Leap to Normative Development}

There have been plenty of discussions in the literature about what a mature space traffic management system will need to look like, but there is also a need to address how such a system might emerge. This is a particularly important question in light of a resurgence of military posturing in the space domain discussed in section II above. There has been discussion about whether such a system will be the result of a topdown or bottom-up process; i.e., will STM be the result of an international mechanism such as a treaty that flows obligations down to the national level or will it be the result of domestic action that rises up to create international norms [72]. This binary discourse is somewhat too simplistic, and more likely the emergence of space traffic management will be from a "stew" of activity from which norms emerge and slowly take shape. This process will begin not with a definitive system of STM, but from a system of space traffic coordination, through which various operators begin coordinate activities for increased safety of operations. The modes and methods of this coordination will likely serve as the initial strands through which space traffic management is normatively defined.

As discussed in Section III, there is already evidence of this stew of norm creation surrounding space traffic management represented by both international and domestic actions. While as of yet there is no clarity on specific norms that might constitute the "management" of space activity, there does seem to be an emerging norm of information sharing that underpins coordination activities, even if those activities occur in an ad hoc manner. Such a norm is in line with the broad goals of the Outer Space Treaty, which contains as one of its core principles the idea of cooperation and exchange of information. Noted earlier, this author has argued in the past that an unwritten component of Article IX of the Outer Space Treaty is the need for de minimis information sharing [33]. This need is implicit in the reciprocal consultation right and obligation. In other words, if a state party is to be able to request a consultation regarding potential harmful interference, then that state party must be privy to a de minimis amount of information about other state party's activities.

Of course, one of the central flaws in the information sharing regime that the treaty regime adopts is the fact that most of these obligations are soft in nature, are implied (such as the de minimis information sharing), or use escape clauses such as "to the greatest extent feasible and practicable" as found in Article XI. The minimal information requested by the Registration Convention is the hardest of these obligations, and there are a number of cases in which the information is not provided or is flawed. This means while there is a norm of information sharing that in some cases rises to a level of obligation, enforcing an action for the breach of such would be difficult due to the softness in the regime.

This perspective though is present day one. Our task herein is to understand how the future regime might take shape, and it seems undeniable that information sharing will be a foundational component in establishing the types of coordination from which space traffic management might emerge. At either the national or international level space traffic management will be an impossibility without proper SSA data and modelling algorithms [73]. This means that SSA data standards and sharing will be a necessary precursor to space traffic management. As an emerging norm, though, data sharing also will help form the necessary norms needed for space traffic management by enabling ad hoc coordination of space activities. As more operators need to coordinate to protect the safety of their own spacecraft and the space environment generally, open SSA data will be the necessary common language for that cooperation, and open source reliable data will be the best platform on which to build such coordination. This is because open data architectures, using the vocabulary of the US SPD-3, can help to build a shared knowledge base that can be trusted by the stakeholders. 
As operators pursue space traffic coordination, they will begin building practice and evidence of what constitutes responsible or reasonable behavior in the space regime. This normative output can build the foundation on which the technical aspects of space traffic management can be built. It is important to understand this as a technical rather than political problem, because states are much more comfortable with regimes for solutions to technical problems, such as international frequency allocation and the ITU, than they are with regimes to political problems. Technical solutions give states the ability to submit to international management in spheres of need without the appearance of relinquishing their sovereignty. Of course, any submission to an international authority represents some loss of autonomy, but specialized technical international organizations have had much more success due to a real and perceived need to manage areas of common usage [74]. This can clearly be seen in the ITU's competency over international telecommunications. The ITU, through its binding Radio Regulations, adopts rules to manage the use of radio frequency from a technical perspective, but the ITU stays clear of attempting to regulate the content of the messages moving over those airwaves (except for in some instances such as safety services). This is an important division as different contingents of states would be unlikely to submit to ITU rules that addressed the content of messages, which is viewed as a domestic issue subject to domestic laws.

As operators share information, best practices may emerge. Best practices can harden into policy or law at the domestic or international level, and in highly technical areas, there is often a preference for the emergence of practice before the imposition of law. For example, the Uniform Commercial Code is based on longstanding practice of merchants. This is where we currently stand with regard to space traffic management, and the development of norms will not be an immediate process. There is a baseline norm that supports SSA information sharing, as well as other information sharing on space activities. This norm is there to better enable space operators to ensure their own safety of operations by enabling coordination mechanisms. Coordination mechanism can lead to best practices, which will inform any future potential rules establishing an STM system.

\section{The Liability Trap}

As noted above, the need for STM is linked to the need for the safety and security of operations. The increasing population of both the debris and operational satellite population puts stress on the space environment, and the potential for new conjunctions leads to instability for all operators, especially when these are in LEO or valuable orbits such as GEO. The oft discussed Kessler Syndrome, in which the debris population hits a tipping point in which it begins to grow from debris colliding with debris, is indicative of this problem, and some argue that we have already passed that tipping point [75]. The need for safety and security is linked directly to the viability of the space environment to maintain human use, and there is wide discourse on the idea that addressing sustainability of the space environment is an urgent and critical need.

This is problematic when we think about how other terrestrial rules regimes have emerged in a trial and error sort of way. Generally speaking, when new activities emerge, they are usually unregulated. At some point, an activity will lead to an incident with the potential for liability. Courts then step in to make determinations about which party is liable, and the decisions of courts shape the rules that emerge to govern these activities. In general, this system works as it allows legislative bodies to perceive real problems and institute rules that lead to greater predictability, but this is a reactionary approach to lawmaking. While it must be noted that the Liability Convention [76] does indeed set out a liability dispute resolution regime for outer space, it does very little to clarify what might constitute fault under its Article III. This is because fault is always a case by case analysis that is informed by past practice and rules of law.

However, this is a dangerous proposition in the space environment, which is already under the strain of usage. Take for instance the Iridium Cosmos collision that occurred in 2009. In this collision, an active Iridium satellite collided with a nonoperational Russian satellite. This incident was the first conjunction of two satellites and created thousands of pieces of debris, most of which is still in orbit [77]. While questions of liability for this collision were settled behind closed doors, it illustrates the issue of waiting on rules of liability in the space context. The break-up of these two satellites has resulted in a large debris cloud in low earth orbit, and that debris will remain in orbit from decades to centuries [78]. The space environment will not be able to bear a wait and see approach to identify the rules needed for predictability based on past liability outcomes, as more incidents like Iridium-Cosmos will result in large portions of the orbital environment being unusable. Indeed, the trend towards the development of very large constellations makes such collision statistically more likely.

Space traffic coordination needs to focus not on how liability might play out, which could result in operators playing "chicken" with each other, but rather on how to best cooperate to preserve the space environment. Indeed, the goal of space traffic coordination-and space traffic managemen$\mathrm{t}-\mathrm{is}$ to prevent future collisions, not to allocate liability for potential collisions, though compliance, or lack thereof, with rules and best practices will be strong evidence in any resulting liability actions.

The challenge then is to balance between the need for coordination and eventually management without waiting for liability incidents to occur. This challenge is important as the cost of access to space continues to decrease and new players enter the field. While established companies with valuable assets on orbit are often proponents of rules of predictability, new actors are often resistant to rules. For instance, the company Swarm Technologies was denied a license by the US Federal Communications Commission for the operation of four test satellites in 2018 [79]. This license was denied on the grounds that the satellites were too small to be effectively tracked by the space surveillance network and as a result did not comply with FCC debris mitigation 
rules. Swarm was a new entrant to the space field and was operated using a Silicon Valley mentality of "ask for forgiveness, not permission," a philosophy that was quite adept at developing businesses on a platform such as the Internet. Thus, despite the lack of a license from the FCC, Swarm had their satellites launched on an Indian PSLV, resulting in stiff fines from the FCC. It is important to note that the FCC's denial of Swarms license was based on the idea that the United States would not be able to collect actionable data on the satellites, the natural result of which is that the US would then be unable to share information on these activities with other operators.

The transition from space traffic coordination to space traffic management may be strained due to these parameters. Both states and private entities seem to be comfortable with ad hoc coordination that does not lead to actual oversight by an authority. At the same time, the types of incidents that often lead to the establishment of governing regimes can be destructive to the space environment and compromise operations for decades to come. From the perspective of norm creation and emergence, it is difficult to predict what types of conditions may lead to more robust, formalized coordination or management, but there does seem to be general agreement that the risk posed by the current ad hoc system will be untenable into the future.

\section{Conclusion}

This article began with a reflection on the idea of instant customary international law. To some extent, instant custom is indicative of historical space law making in general. Not only did norms of customary international space law emerge quickly, but treaty instruments also emerged almost immediately after the dawn of the space age. For a variety of reasons, this process has slowed significantly, and while there are numerous gaps in the space law regime, there does not seem to be an immediate desire by states to reengage in the lawmaking process.

It may be time to shift the discourse away from impatiently waiting for new treaty instruments to secure safety and sustainability in outer space and focus on the processes of norm "life cycles" as postulated by Finnemore and Sikkink [80]. The norm lifecycle is a three-stage process in which there is first "norm emergence," then acceptance in a "norm cascade", followed by internalization of the accepted norms [81]. When it comes to space traffic management, we are still very much in the first stage of norm emergence in which "norm entrepreneurs" seek to "convince a critical mass of states... to embrace new norms" [81]. If these norm entrepreneurs are successful, there will be a "tipping point" followed by the norm cascade in which that critical mass of states accepts the potential norm [81]. As has been shown above the norm of open SSA, data sharing may be reaching such a tipping point, especially if more of the larger space actors embrace it. However, other normative aspects of the space traffic management enterprise are still lacking in definition and yet to emerge. Barring a sudden change in geopolitics or perhaps a catastrophic on orbit conjunction, the norm lifecycle will take time as operators need to define what constitutes responsible behavior in this context.

Based on current state practice, it is difficult to predict how a multilateral space traffic management system could emerge, but it is submitted here that the best clues we have are to examine the emergence of space traffic coordination that result from wider information sharing. If information sharing on space operations and SSA data continues to develop along normative lines, then, there will be ample opportunities for space actors and their supervising states to influence the future of space traffic management. The key hurdle in this endeavor is overcoming the resistance to multilateral efforts at securing outer space that currently dominates the international relations concerning space activities. As the technical challenge of maintaining safety, security, and sustainability of outer space, though, states may have no choice but to engage in cooperative efforts to preserve their own access and usage of the space environment.

\section{Data Availability}

The data used to support the study is available within the article.

\section{Conflicts of Interest}

The authors declare no conflict of interests regarding the publication of the article.

\section{References}

[1] M. N. Shaw, International Law, Cambridge University Press, 4th edition, 2001.

[2] M. Dixon, Textbook on International Law, Oxford University Press, 7th edition, 2012.

[3] B. Cheng, "United Nations Resolutions on Outer Space:'Instant' International Customary Law?," Indian Journal of International Law, vol. 5, p. 23, 1965.

[4] B. Cheng and Shaw, International Law61-62.

[5] Dixon, Textbook on International Law36.

[6] Shaw, International Law61-62.

[7] S. Marchisio, "The Evolutionary Stages of the Legal Subcommittee of the United Nations Committee on the Peaceful Uses of Outer Space (COPUOS)," J. Space L., vol. 31, p. 219, 2005.

[8] B. Israel, Treaty Stasis [Agora: The End of Treaties?], AJIL Unbound (blog), 2014, https://www.asil.org/blogs/treatystasis-agora-end-treaties.

[9] P. J. Blount, "Renovating Space: The Future of International Space Law,” Denv. J. Int'l L. \& Pol'y, vol. 40, pp. 515-686, 2012.

[10] P. Meyer, "The Diplomacy of Space Security: Whither the International Code of Conduct?," in Simons Papers in Security and Development, Simon Fraser University, Vancouver, 2014, http://summit.sfu.ca/item/14921 at 5 .

[11] "For instance the most recent of these is UNGA Res. 75-35: Prevention of an Arms Race in Outer Space, UN Doc. $\mathrm{A} / \mathrm{RES} / 75 / 35$," the United States and Israel voted against this resolution, 2020.

[12] "Draft Treaty on the Prevention of the Placement of Weapons in Outer Space, the Threat or Use of Force against Outer Space Objects," 2014, https://reachingcriticalwill.org/images/ 
documents/Disarmament-fora/cd/2014/documents/PPWT2 014.pdf.

[13] On the Conference on Disarmament generally, NIT, "Conference on Disarmament," 2020, https://www.nti.org/learn/ treaties-and-regimes/conference-on-disarmament/.

[14] P. J. Blount, "Space Security and the Law of International Cooperation: The Need for Leadership and Coordination," Indian Journal of Air and Space Law, pp. 1-16, 2020, 8.

[15] Meyer, "The Diplomacy of Space Security," in Space Code of Conduct Mugged in New York, M. Krepon, Ed., Arms Control Wonk, 2015, https://www.armscontrolwonk.com/archive/ 404712/space-code-of-conduct-mugged-in-new-york/.

[16] P. J. Blount, "Sorting Out Self-Defence in Space: Understanding the Conflicting Views on Self-Defence in the EU Code of Conduct," in Maria Manoli and Sandy Belle Habachi, Conflicts in Space and the Rule of Law, Ed., McGill University, Montreal, 2017.

[17] S. Bajrami and S. Talmon, "United Nations Disarmament Yearbook 2019: Part II (2019)," in Preventing an arms race in outer space and political game-play at the United Nations, pp. 185-186, German Practice in International Law, 2020, https://gpil.jura.uni-bonn.de/2020/02/preventing-an-armsrace-in-outer-space-and-political-game-play-at-the-unitednations/.

[18] P. J. Blount, "The shifting sands of space security: the politics and law of the peaceful uses of outer space," Indonesian Journal of International Law, vol. 17, pp. 1-18, 2019.

[19] On ASATs and L. Grego, A History of Anti-satellite Programs, Union of Concerned Scientists, 2012, http://ucsusa.org/sites/ default/files/legacy/assets/documents/nwgs/a-history-ofASAT-programs_lo-res.pdf.

[20] P. J. Blount and J. I. Gabrynowicz, "USA-193: Selected Documents (National Center for Remote Sensing, Air, and Space Law, 2009)," in Mission Shakti: Read PM Narendra Modi's full speech announcing how India took down satellite, p. 3, India Today, 2019, https://www.indiatoday.in/india/story/missionshakti-narendra-modi-fullspeech-1487838-2019-03-27.

[21] A. Rej, "Russia Tests Anti-Satellite Missile: US," The Diplomat, 2020, https://thediplomat.com/2020/12/russia-tests-antisatellite-missile-us/.

[22] "On new military branches see Space Policy Directive-4: Establishment of the United States Space Force," 2019, https://www.whitehouse.gov/presidential-actions/text-spacepolicy-directive-4-establishment-united-statesspace-force/.

[23] "Macron announces creation of French space force," France, 2019https://www.france24.com/en/20190713-macron-francespace-force.

[24] S. Knapton, "Ministry of Defence preparing for space war within the next 15 years," The Telegraph, 2019, https://www .telegraph.co.uk/science/2019/09/27/ministry-defencepreparing-space-warwithin-next-15-years/.

[25] M. Yamaguchi, "Japan to set up its own space force," The Australian, 2020, https://www.theaustralian.com.au/world/japanto-set-up-its-own-space-force/news-story/9a005c070795 3584e94539be2ea8813f.

[26] C. Todd Lopez, "Shanahan: Space No Longer Peaceful," U.S. Department of Defense, 2019, https://www.defense.gov/ explore/story/Article/1810085/shanahan-space-no-longerpeaceful/.

[27] ICAO, “Air Traffic Management," n.d., https://www.icao.int/ safety/airnavigation/pages/atm.aspx.
[28] Skybrary, “Air Traffic Management," 2020, https://www. skybrary.aero/index.php/Air_Traffic_Management_(ATM).

[29] K. W. Abbott and D. Snidal, "Hard and Soft Law In International Governance," International Organization, vol. 54, no. 3, pp. 422-423, 2000.

[30] I. Marboe, Soft Law in Outer Space: The Function of Nonbinding Norms in International Space Law, Böhlau Verlag, 2012.

[31] "Agreement Between the Government of The United States of America and the Government of The Union of Soviet Socialist Republics on the Prevention of Incidents On and Over the High Seas," 1972, https://2009-2017.state.gov/t/isn/4791.htm.

[32] "International Code of Conduct against Ballistic Missile Proliferation, UN Doc. A/57/724," 2003, https://www.hcoc.at/ documents/Hague-Code-of-Conduct-A_57_724-English.pdf.

[33] P. J. Blount, "Developments in space security and their legal implications," Law/Technology, vol. 44, p. 2, 2011.

[34] Treaty on Principles Governing the Activities of States in the Exploration and Use of Outer Space, including the Moon and Other Celestial Bodies, 610 UNTS 205 (entered into force 10 October 1967) [hereinafter Outer Space Treaty], P. Dembling, and D. Arons, "The Evolution of the Outer Space Treaty," Journal of Air Law and Commerce, vol. 33, pp. 419456, 1967.

[35] F. Lyall and P. B. Larsen, Space Law: A Treatise, Ashgate Publishing, Ltd., 2013.

[36] United Nations General Assembly, "Resolution 1962 (XVIII): Declaration of Legal Principles Governing the Activities of States in the Exploration and Use of Outer Space," 1963.

[37] P. J. Blount, "Innovating the law: fifty years of the outer space treaty," in Innovation in Outer Space: International and African Perspectives, M. Hofmann and P. J. Blount, Eds., pp. 31-52, Nomos Press, 2018.

[38] Lyall \& Larsen, "Convention on Registration of Objects Launched into Outer Space, 1023 U.N.T.S. 15," Space Law, pp. 84-96, 1976.

[39] M. Chatzipanagiotis, "Registration of Space Objects and Transfer of Ownership in Orbit/Zur Registrierung von Weltraumgegenstanden Und Eigentumsubertragung Im Weltraum/L'Enregistrement Des Objets Spatiaux et Le Transfer de Propriete Dans l'Espace," ZLW, vol. 56, p. 229, 2007.

[40] UNOOSA, "United Nations Register of Objects Launched into Outer Space,” n.d., https://www.unoosa.org/oosa/en/space objectregister/index.html.

[41] UNOOSA, United Nations Register of Space Objects, "It should also be noted that states that are not party to the Registration Convention may register their space objects with the UN Registry under a pre-existing process detailed in UN General Assembly Resolution 1721 (XVI) International Cooperation in the Peaceful Uses of Outer Space," On the distinction between the two see Lyall \& Larsen, Space Law, 1961.

[42] M. Jah et al., 2020, https://twitter.com/moribajah/status/ 1326937469972074497 ? $\mathrm{s}=20$.

[43] the PROBA satellite and J.-F. Mayence, "Belgian Legal Framework for Earth Observation Activities," Journal of Space Law, vol. 89, pp. 92-94.

[44] UNOOSA, "Outer Space Objects Index," n.d., https://www.un oosa.org/oosa/osoindex/index.jspx?lf_id.

[45] Inter-agency Space Debris Coordination Committee, "IADC Space Debris Mitigation Guidelines," 2007. 
[46] UNOOSA, "Space Debris Mitigation Guidelines of the Committee on the Peaceful Uses of Outer Space," 2010, https:// www.unoosa.org/pdf/publications/st_space_49E.pdf.

[47] UNCOPUOS, "Guidelines for the Long-term Sustainability of Outer Space Activities, U.N. Doc. A/AC.105/2018/CRP.20," 2018.

[48] Of course technical guidelines and implementations can have their own degree of regulatory power. See generally, Lawrence Lessig, Code 2.0 (Basic Books, 2006) and K. Jayakar, "Globalization and the Legitimacy of International Telecommunications Standard-Setting Organizations," Indiana Journal of Global Legal Studies, vol. 5, pp. 711-738, 1998.

[49] M. Mejia-Kaiser, "The Geostationary Ring: Practice and Law," in International Regulations of Space COmmunications: Current Issues (Larcier 2013), M. Hofmann, Ed., pp. 199-244, Lyall and Larsen, Space Law, 2020.

[50] Constitution of the International Telecommunication Union, 2010.

[51] F. G. von der Dunk, "Maintaining the Master International Frequency Register," International Regulations of Space COmmunications: Current Issues, 2013.

[52] P. Stubbe, "New Definition of 'Bringing into Use' in the Radio Regulations," International Regulations of Space COmmunications: Current Issues, 2013.

[53] G. Oberst, Dispute Resolution before the ITU: The Operators Experience, M. Hofmann, Ed., Dispute Settlement in the Area of Space Communications, 2015.

[54] C. Crosier, "United States Strategic Command Space Situational Awareness Sharing Program Update, presentation at the United Nations Committee on the Peaceful Uses of Outer Space Scientific and Technical Subcommittee 54th Session," 2019, https://www.unoosa.org/documents/pdf/copuos/stsc/ 2017/tech-34E.pdf.

[55] 10 U.S.C. $\$ 2274$.

[56] T. Chow, "Space Situational Awareness Sharing Program: An SWF Issue Brief," 2011, https://swfound.org/media/3584/ssa_ sharing_program_issue_brief_nov2011.pdf.

[57] Crosier, "United States Strategic Command Space Situational Awareness Sharing Program Update".

[58] "See Space Traffic Management: How to Prevent a Real Life "Gravity": Hearing Before the Subcomm. on Space of the H. Comm. on Science, Space, and Technology," Cong, vol. 113, pp. 113-174, 2014, https://docs.house.gov/meetings/SY/ SY16/20140509/102218/HHRG-113-SY16-Wstate-BlountP20140509.pdf.

[59] “Space Policy Directive-3, National Space Traffic Management Policy," 2018, https://www.whitehouse.gov/presidentialactions/space-policy-directive-3-national-space-trafficmanagement-policy/.

[60] SPD-3 at Sec. 6.

[61] SPD-3 at Sec. 5(c)(iii).

[62] SPD-3 at Sec. 5(a)(ii).

[63] B. Lal et al., Global Trends in Space Situational Awareness (SSA) and Space Traffic Management (STM), Institute for Defense Analysis, 2018.

[64] Lal et al., Global Trends50.

[65] Lal et al., Global Trends, and European Space Policy Institute, Towards a European Approach to Space Traffic Management, 2020.

[66] "Luxembourg and NorthStar to create Centre of Excellence for Clean Space," 2019, https://gouvernement.lu/en/actualites/ toutes_actualites/communiques/2019/12-decembre/19schnieder-northstar.html.

[67] S. Al Hajeri, "Space Traffic Management, presentation at the United Nations Committee on the Peaceful Uses of Outer Legal Subcommittee 58th Session," 2019, https://www .unoosa.org/documents/pdf/copuos/lsc/2019/tech-04E.pdf.

[68] Exoanalytic Solutionshttps://exoanalytic.com/.

[69] Leolabshttps://www.leolabs.space/.

[70] Space Data Associationhttps://www.space-data.org/sda/.

[71] M. Smith, "Space data association and USSTRATCOM reach data sharing agreement," Space Policy Online, 2014, https:// spacepolicyonline.com/news/space-data-association-andusstratcom-reach-data-sharing-agreement/.

[72] S. A. Kaiser, "Space Traffic Management: Not Just Air Traffic Management for Outer Space and More than Data Analytics," The Proceedings of the International Institute of Space Law 2019, 2020, and Yu Takeuchi, "Ignitions for Global STM RuleMaking Processes Legal Perspectives on Why Operators Have to Take Initiatives," 345-346, in P.J. Blount et al., The Proceedings of the International Institute of Space Law 2019 (Eleven 2020).

[73] P. J. Blount, "Space traffic management: standardizing onorbit behavior," AJIL Unbound, vol. 113, pp. 120-124, 2019.

[74] G. Blum, "Bilateralism, Multilateralism, and the Architecture of International Law," Harvard International Law Journal, vol. 323, pp. 354-355, 2008.

[75] D. J. Kessler and B. G. Cour-Palais, "Collision frequency of artificial satellites: the creation of a Debris Belt," Journal of Geophysical Research., vol. 83, no. A6, p. 2637, 1978.

[76] "Convention on International Liability for Damage Caused by Space Objects," 1972.

[77] Secure World Foundation, "2009 Iridium-Cosmos Collision Fact Sheet," 2010, https://swfound.org/media/6575/swf_ iridium_cosmos_collision_fact_sheet_updated_2012.pdf.

[78] Secure World Foundation, "2009 Iridium-Cosmos Collision Fact Sheet".

[79] C. Henry, "FCC fines swarm $\$ 900,000$ for unauthorized smallsat launch," Space News, 2018, https://spacenews.com/fccfines-swarm-900000-for-unauthorized-smallsat-launch/.

[80] M. Finnemore and K. Sikkink, "International Norm Dynamics and Political Change," International Organization, vol. 52, no. 4, pp. 887-917, 1998.

[81] Finnermore \& Sikkink, "International Norm Dynamics895. 